3. De Marchis E, Knox M, Hessler D, et al. Physician burnout and higher clinic capacity to address patients' social needs. J Am Board Fam Med 2019;32:69-78.

4. Thornton RL, Glover CM, Cené CW, Glik DC, Henderson JA, Williams DR. Evaluating strategies for reducing health disparities by addressing the social determinants of health. Health Aff (Millwood) 2016;35:1416-23.

doi: 10.3122/jabfm.2019.05.190122

The above letter was referred to the author of the article in question, who offers the following reply.

\section{Response: Re: Physician Burnout and Higher Clinic Capacity to Address Patients' Social Needs}

To the Editor: We thank Ingerick and Iuga for their interest in our work on provider burnout. ${ }^{1}$ Our findings suggested that family physicians working in clinical settings equipped to address patients' social risk factors had lower odds of reporting burnout symptoms. The results highlight an underexplored rationale for bolstering clinic-based social services: these services may decrease clinician burnout. Clinic-level strategies to collect and respond to social risk dataand the multi-level impacts of these strategies-should be the focus of future research.

Emilia H. De Marchis, MD, MAS Department of Family \& Community Medicine, University of California-San Francisco, San Francisco, CA emilia.demarchis@ucsf.edu

Danielle Hessler, $\mathrm{PhD}$

Laura M. Gottlieb, MD, MPH

To see this article online, please go to: http://jabfm.org/content/ 32/5/000.full.

\section{Reference}

1. De Marchis EH, Knox M, Hessler D, et al. Perceived clinic capacity to address patients' social needs and family physician burnout. J Am Board Fam Med 2018;32:69-78.

Funding Statement: This publication was supported by a fellowship training grant by the National Research Service Award (NRSA) T32HP19025. Its contents are solely the responsibility of the authors and do not represent the official views of NRSA.

doi: 10.3122/jabfm.2019.05.190219

\section{Re: Signs and Symptoms That Rule Out Community-Acquired Pneumonia in Outpatient Adults: A Systematic Review and Meta-Analysis}

To the Editor: Dr. Marchello et $\mathrm{al}^{1}$ make an important contribution to clinical medicine and patient care by creating evidence for how to combine key clinical findings to confidently position the possibility of pneumonia in adults further down in the differential diagnosis in patients with acute respiratory illness. Although their findings seem to ring true from clinical experience, their clinical tool requires prospective validation per the authors.

While most family physicians currently do not have point-of-care ultrasound (POCUS), the majority will in the future. Use of pocket ultrasound is becoming common among medical students, training in family medicine residencies is increasing, and POCUS continued medical education training is very accessible. Point-ofcare lung ultrasound (POCLUS) is more reliable than a chest radiograph to rule in or rule out pneumonia in adults and children. 2,3,4,5 The author's suggested future prospective research might also include a research arm to evaluate the potential additive benefit of combining POCLUS with their clinical decision-making tool.

Respectfully submitted,

Louis A. Kazal, Jr., MD, FAAFP

Associate Professor, Department of Community and Family Medicine, Geisel School of Medicine at Dartmouth, Hanover, New Hampshire louis.a.kazal@dartmouth.edu

To see this article online, please go to: http://jabfm.org/content/ 32/5/000. full.

\section{References}

1. Marchello CS, Ebell MH, Dale AP, Harvill ET, Shen Y, Whalen CS. Signs and symptoms that rule out communityacquired pneumonia in outpatient adults: a systematic review and meta-analysis. J Am Board Fam Med March 2019;32: 234-247.

2. Kaysin A, Viera AJ. Adults: diagnosis and management. Am Fam Physician 2016;94:698-706.

3. Ye X, Xiao H, Chen B, Zhang S. Accuracy of lung ultrasonography versus chest radiography for the diagnosis of adult community-acquired pneumonia: review of the literature and meta-analysis. PLoS One 2015;10:e130066.

4. Chavez MA, Shams N, Ellington LE, et al. Lung ultrasound for the diagnosis of pneumonia in adults: a systematic review and meta-analysis. Respir Res 2014;15:50.

5. Samson F, Gorostiza I, González A, Landa M, Ruiz L, Grau M. Prospective evaluation of clinical lung ultrasonography in the diagnosis of community-acquired pneumonia in a pediatric emergency department. Eur J Emerg Med. 2018;25:65-70.

doi: 10.3122/jabfm.2019.05.190132

The above letter was referred to the author of the article in question, who offers the following reply.

\section{Response: Re: Signs and Symptoms That Rule Out Community-Acquired Pneumonia in Outpatient Adults: A Systematic Review and Meta-Analysis}

To the Editor: We thank Dr. Kazal for the comment on our publication "Signs and Symptoms That Rule out Community-Acquired Pneumonia in Outpatient Adults: A Systematic Review and Meta-Analysis."1 Not only is lung ultrasonography a possible alternative to chest radiography (CXR) for the diagnosis of community-acquired pneumo- 